\title{
A Study on Finding the Factors, Hindering the use of digital wallets among youth in Developing Countries.
}

\author{
A.T. Nimansa ${ }^{1}$ \\ Faculty of Graduate Studies and Research, Sri Lanka Institute of Information Technology, \\ Malabe, Sri Lanka. \\ Dr. N. Kuruwitaarachchi ${ }^{2}$ \\ Faculty of Technology, University of Sri Jayewardenepura, Gangodawila, Nugegoda \\ Sri Lanka.
}

\begin{abstract}
A digital wallet or eWallet is a mobile based software application that securely persists consumer's payment information and passwords for numerous payment methods. By using an eWallet, users can complete their transactions easily and quickly with technologies such as Quick Response (QR) and near-field communications (NFC). In the modern world, people use digital wallets to engage in financial and non-financial activities using the internet. It stores physical financial instruments digitally and provides high availability to convenience to the user. Typically, to facilitate high security to those financial assets, in the digital wallet of the user, and to maintain reliability and availability, mobile application developing organizations follow different authorization mechanisms. The problem prevailing in a developing country similar to Sri Lanka is the less use of digital wallets in day to day transactions. The final outcome of the research will be to find the factors which affect the use of digital wallets in Sri Lankan students who study in western province universities. The advantage of finding the mentioned factors is to help eWallet developers to enhance their products to attract and onboard more customers. The eWallet developers can think about these measures when developing a solution and use it to promote the application. Further, when developers create an optimal solution, the consumer of eWallets will be highly benefited with an efficient financial application.
\end{abstract}

Keywords: eWallet, digital wallet, UTAUT-3, Unified theory of acceptance and use of technology - 3, user adoption, behavioral intention

\section{INTRODUCTION}

Information systems and processes in the Corporate environment are rapidly evolving and often subjected to digitalization [1]. In a digital era, more focus is driven towards innovations in financial processes. Organizations in third world countries like Sri Lanka are following a traditional method of transaction settlement [2]. Studies say that Sri Lankans use their debit cards/ account passbooks to withdraw their money and use physical cash for their daily expenses and the percentage use of new applications such as mobile cash and online banking has been less than $01 \%$ and comparatively insignificant [2]. Employees in the country who have an educational level of GCE Advanced Level and above display contrast in the previously stated behavior in handling their expenses due to the increase of computer literacy. As per Computer Literacy Statistics - 2018 (First six months) Department of Census and Statistics Sri Lanka, a person (aged 5-69) is considered as a computer literate person if he/she could use a computer on his/her own. For example, even if a 5 years old child can play a computer game then he/she is considered a computer literate person [6]. The statistic also demonstrates that the computer literacy of individuals who have an educational level of GCE 
Advanced Level and above is 70\% [6]. They tend to use digital banking; wallets and they follow a minimal use of physical cash. Mobile wallets have numerous advantages for the customer as well as the merchant and the most significant benefits are the time saved and the ease of use.

Mobile wallets are one of the prepaid payment instruments [7]. Further, it is a digital alter-ego of the physical wallet [12]. Digital Wallet is a mobile application which allows its consumers to perform electronic financial transactions, just as they hold her physical wallet with cash, debit cards, credit cards, pre-paid cards driver's license, transportation passes, etc. Digital wallets allow the user to carry almost everything that a physical wallet does.

At the initial stage of introducing digital wallets to the consumers, the banking industry researchers predicted that mobile wallets would rapidly replace consumer's use of cash and plastic cards. The mobile wallets haven't exactly taken off as per the prediction. Consumers are interested in using mobile wallets, but the reality is that mobile wallets still need improvements to convert into a widespread product. Studies in Sri Lanka shows that embracing or use of digital banking and mobile banking except for ATM services by consumers is less than $01 \%$ [23]. This percentage is insignificant and the Motivation behind this is to find out the preference towards mobile wallets, of a selected sample of consumers in Sri Lanka.

According to the statistics in Tencent 2019, WeChat and AliPay Digital wallets have the highest number of active users which exceeds One Billion users. The next in line is PayPal which has 250 million active users. [1]

According to a study done on the Impact of e-wallets for the current generation, [44] the following advantages and impact those factors create on the current generation are identified.

1. Offers more convenience for many consumers $(33.3 \%)$

2. Offer access to new rewards $(22.2 \%)$

3. Help you with your Budget (17.8)

4. Can be paid to other services $(14.4 \%)$

5. High availability $(12.2 \%)$

The statistics showed that Sri Lanka being a developing country has high computer literacy when the educated population is considered (GCE Advanced Level or above) and Sri Lankans currently use other latest digital finance services.

\section{LITERATURE REVIEW}

As per the world development report background papers, the number of young people is reaching unprecedented levels in most developing countries [52]. In many countries, especially in East Asia and Latin America, youth populations are at or near their peak [52]. Sri Lanka is considered as a developing country and as per the world bank reports on Sri Lanka, it is a lower middle-income country with an average per person GDP of USD 3,852 and a total population of 21.8 million.

Since the youth represents the future of a country, behaviour of youth towards technology reflects a country's adoption to the same. The youth population in Sri Lanka is estimated to be around 4.4 million or $23 \%$ of the total population based on 2012 statistics.

It is shown that eWallet usage needs specific technological skills or computer literacy. Since mostly educated youth are computer literate, this study will be conducted among university students in Sri Lanka. The highest number of universities are located in the western province of Sri Lanka and in my point of view finding the factors, hindering the use of digital wallets among youth in developing countries will be clearly reflected through the responses of Sri Lankan students, who study in universities located in the western province of the country. 


\section{A. eWallet Usage in Sri Lanka}

The mode of delivering services to the customers by financial institutions has changed over the years and the use of information and telecommunication technologies within the financial industry shows explosive growth. A Journal by an Indian author Bhagyashri R. Pachpande and Aakash A. Kamble states that the Senior President of Yes Bank said: "Prepaid wallets will increasingly replace cash in the near future. The debit and credit cards will not be replaced, but those instruments will be used for specific requirements and micro transactions". Hence it is known that digital wallets are gradually replacing the traditional transaction mechanisms [3]. A study by the Faculty of Management and Commerce, South Eastern University of Sri Lanka shows that there are 25 commercial banks both state and non-state throughout the country [2]. Nearly all the banks in Sri Lanka provide mobile banking applications and some of the Banking and non-banking institutions provide digital wallets as well.

Due to the unavailability of reliable sources to identify the exact number of digital wallet users in Sri Lanka, the total wallet downloads of each wallet application through Google play is considered. Considering the top five digital wallet applications in Sri Lanka, an average will be derived. According to the annual reports of Lanka Pay, there are five main issuer banks/financial organizations which have enabled JustPay. JustPay is one of the latest trends in payment products of LankaPay, which allows consumers to make retail payments up to Rs. 10,000 in value using smart mobile devices by transferring funds from their account(s) to the merchant's account directly [15]. Assuming that the active users will be in the highest downloaded digital wallet apps group of consumers, five sample apps are taken into consideration. The eWallet usage in Sri Lanka is approximately $\sim 0.38 \%$.

Using the above derived approximate percentage of wallet usage, the gap between the wallet usage of the other eight countries and Sri Lanka is compared below [13].

\begin{tabular}{|l|l|l|}
\hline Country & Percentage (a) & $\begin{array}{l}\text { Gap in Sri } \\
\text { Lanka (a)-0.38\% }\end{array}$ \\
\hline China & $47 \%$ & $46.6200 \%$ \\
\hline Norway & $42 \%$ & $41.6200 \%$ \\
\hline UK & $24 \%$ & $23.6200 \%$ \\
\hline Japan & $20 \%$ & $19.6200 \%$ \\
\hline Australia & $19 \%$ & $18.6200 \%$ \\
\hline Colombia & $19 \%$ & $18.6200 \%$ \\
\hline United States & $17 \%$ & $16.6200 \%$ \\
\hline Singapore & $17 \%$ & $16.6200 \%$ \\
\hline
\end{tabular}

Table 1: Wallet Usage Gap in Sri Lanka Compared to other countries

Studies conducted in Sri Lanka by researchers have discovered the issues related to Digital and mobile payments [2]. To identify the factors which affect the usage of digital wallets in Sri Lanka negatively, the famous model namely Unified Theory of Acceptance and Use of Technology (UTAUT3) will be used.

Studies show that the adaptation of modern technology such as digital wallets, mobile banking, online banking, etc other than ATM services in Sri Lanka is less than 1\% which is very insignificant compared to the rest of the world [2]. When the low rate of $1 \%$ is considered, it is questionable whether the money invested in Research and Development of the latest Finance applications will be beneficial to the community at this time period. Due to some of the factors which discourage Sri Lankan customers to switch from traditional payments to Digital wallets implies that the Sri Lankan Banking and finance platform has a customer base who are not mature enough to seize the services they are ready to render. 


\section{B. A Study of Preference Towards the Mobile Wallets Among the University Students in Lucknow City}

"The study says, eWallet was something majority of people in India was not aware a few years back, but its use saw a huge leap in the last couple of years with the surge of smartphones, high-speed internet connectivity using $3 \mathrm{G}$ and $4 \mathrm{G}$ and the lucrative offers mobile wallets provide in India [7]." "The stated study was an attempt to discover the preference towards eWallet among the students studying in various universities in a Indian city called Lucknow city [7]."

The study says the majority of the students prefer to use an eWallet to make a recharge to their phone $(23.15 \%)$ followed by paying bills $(16.84 \%)$ and transferring money (15.78\%). Avoiding long queues, an independent purchase based on time and place, and paying instantly are the three important factors for the students to opt for mobile wallets in India. The study also states that $44 \%$ of those Indian respondents strongly agree with the statement that they prefer to use other cashless payments methods also, out of all the respondents, $31.57 \%$ strongly agree that they are concerned about transaction safety. Further $40 \%$ of students disagree that the cost of data access is high and a similar percentage $(40 \%)$ of them have no issue in trusting the online vendors.

The study also states that there is no significant association between the gender of the respondent and the opinion regarding the future of the mobile wallet fails to reject. The study has discovered that a Significant association is there between the age of the respondents and the opinion regarding the future of eWallet.

\section{Factors Affecting Consumer's Choice to Use Mobile Wallet to Access m-Commerce Industry in India}

"An eWallet can be defined as the digital alternative of the physical wallet" [50]. It stores the digitized valuables for authorization and uses it accordingly to grant permission for accessing goods [50]. The permission is granted by various forms, ranging from the password, QR code, and facial image [50].

In the context of the enormous growth of the m-commerce industry in India, this empirical research was undertaken to determine the factors influencing consumers' choice to use the mobile wallet service. [50]. This paper describes how these factors were determined using Logistic Regression, and Structural Equation Modeling [50].

The Indian mobile wallet market is expected to grow at a CAGR of $140.87 \%$ through 2018 [50]. This growth is characterized by the adoption of smartphones, tablets and other mobile technologies. The business model is all about discounts [50]. There is a perception that mobile wallets are more secure than normal wallets [50]. Market players have yet to identify a strategic difference in the product. In India, Paytm is the biggest player [50].

From the data analysis, it is observed that convenience, promotions, direct billing, and prompt service are important, in that they have a significant impact on the dependent variable [50].

\section{A Model of Factors Influencing Consumers Intention To Use E-Payment System in Indonesia}

The study indicates that in recent years, electronic commerce (electronic commerce) in Indonesia has grown rapidly [51]. E-commerce has become an opportunity for businesses to increase their sales [51]. Electronic payment (electronic payment) was developed to facilitate e-commerce transactions between the consumer and the seller[51]. In this study, the researcher investigated the consumer's intention to use electronic payment [51]. The proposed research model was developed by extending the Unified Theory of Acceptance and Use of Technology (UTAUT-3) with the culture and perceived safety in the model, to determine the significant factors that influence the acceptance of electronic payment technology [51]. The model proposed in the study is used to investigate the consumer's intention to use the electronic payment system in Indonesia, based on UTAUT-3. He states that the factors of UTAUT-3 have a positive effect on the intention to use the electronic payment system [51].

The research indicates that the UTAUT model is a conceptual model that can be used to discover the factors which influence the user's adoption of e-commerce. 


\section{Methodology}

To prove that the Digital wallets have not taken off as expected by the finance apps using the community, a study should be conducted. Designing the study in an achievable manner and creating proper hypotheses should be done in the design phase.

I propose the model of factors influencing consumer's intention to use the eWallet application in Sri Lanka. The proposed model is based on UTAUT-3 to investigate consumer's intention to use eWallet in Sri Lanka. Much research has been developed and modified based on the UTAUT-3 model to get variables that correspond to the context of their research.

\section{A. Research Model}

The objective of this study is to identify factors which affect the use of Digital Wallets in Sri Lankans. Unified Theory of Acceptance and Use of Technology (UTAUT-3) by Farooq et al. (2017) is one of the latest and trending developments in the field of technology acceptance models. It is introduced as a combined or unified model for accepting new information technology based on eight such technology acceptance models. Those models are "Technology Acceptance Model (TAM), Theory of Reasoned Action (TRA), Motivational Model (MM), Theory of Planned Behavior (TPB), Combined TAM and TPB, Model of PC Utilization (MPCU), Innovation Diffusion Theory (IDT) and Social Cognitive Theory (SCT) [27]".

The UTAUT-3 model identifies user goal or intention and adaption as the main dependent variable. [27].

UTAUT-3 has constructs namely "performance expectancy (PE), effort expectancy (EE), social influence (SI), Habit (HB), Hedonic Motivation (HM), Facilitating Conditions (FC), Personal innovativeness in the domain of IT (PI) and Price value (PV)".

Primarily to identify the factors which affect the use of eWallets in Sri Lankans, a focus group discussion was done with ten individuals who are working in a FinTech company as Business Analysts. The discussion was held for 30 minutes and decided that for the research purpose; most suitable and relevant direct determinants are "Performance Expectancy and Effort Expectancy". The variables of SI, HB, HM, FC, PI, PV have been taken out due to its irrelevance to the context.

The two independent variables PE and EE are hypothesized to be determining the behavioral intention (BI) and behavior (UB) to the adoption of eWallet.

Performance Expectancy (PE): Performance expectancy is defined as the degree to which an individual believes that using the system will help him or her to attain gains in job performance [27]. The user's perception of how e-wallets would improve shopping convenience and efficiency is expected to influence the user's adoption intentions. Previous

Studies have confirmed a significant relationship between performance expectations and technology adoption [47].

Therefore, it is hypothesized that;

$\mathrm{H}_{1}$ : PE influence user's behavioral intention to use the e-wallet

Effort Expectancy (EE): Effort expectancy is defined as the degree of ease associated with the use of the system [27].

Therefore, when a user feels that using an eWallet is easy and does not require physical cash or wallet, then the expectation of the effort becomes a strong predictor of the intention to use eWallet. Empirically, the link between the expectation of effort and behavioral intention has been supported by many authors [46,47]. 
Therefore, it is hypothesized that;

$\mathrm{H}_{2}$ : EE influences a user's behavioral intention to use the e-wallet.

Behavioral Intention to use the technology (BI): "BI refers to the behavioral preparation to accept, use, or embrace a particular technology [46]".

It is hypothesized that;

$\mathrm{H}_{3:}$ Behavioral intention influences user's adaptation behavior to e-wallet

B. Measuring Direct Determinants using UTAUT-3 model

According to the UTAUT-3 conceptual model, the relationship between the direct determinants. Multi-item scales from UTAUT-3 instruments [46].

To measure Direct Determinants quantitative survey methodology will be used, in order to generate answers to the research questions by testing hypotheses. Data was collected using a questionnaire that was distributed through Google forms among the target population.

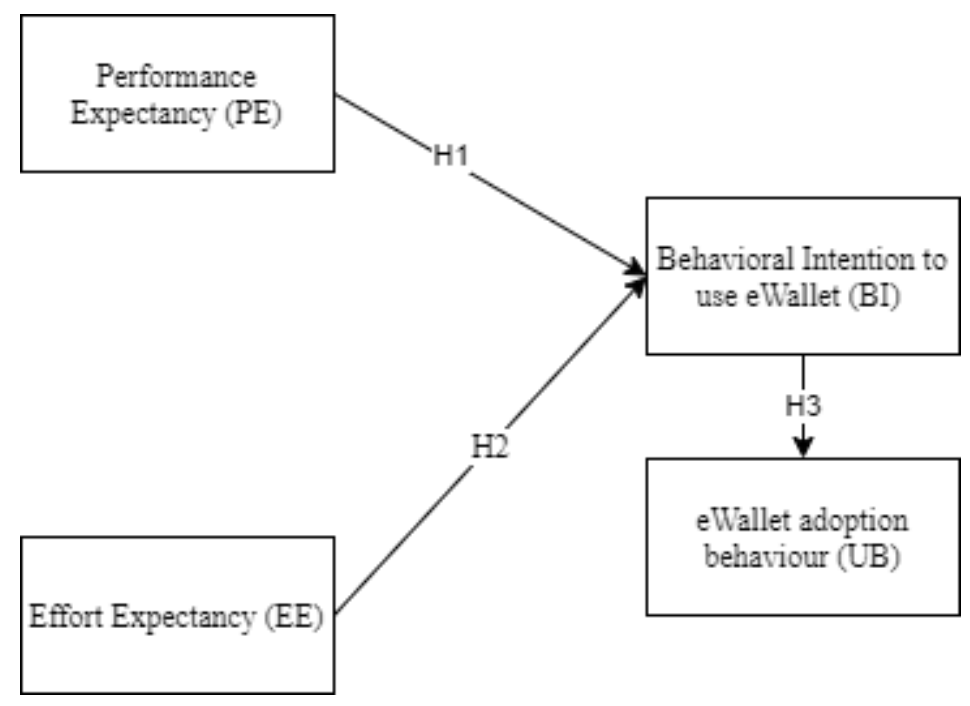

Figure 1: Conceptual Diagram

As the diagram depicts, the independent variables for the research are PE and EE, and the dependent variable is UB.

This model establishes two key determinants of individual eWallet adoption, namely, performance expectancy (PE) and effort expectancy (EE), These factors are mediated by behavioral intention to use (BI) in understanding actual technology utilization behavior (Venkatesh et al., 2012). The extended UTAUT was named as UTAUT-3 with seven significant determinants of IS adoption behavior prediction but for this research, only two of the direct determinants will be used.

C. Research Design

In this chapter, the process of conducting the research is explained. Deriving the hypothesis, population selection, sample selection and process of gathering data for final data analysis is described.

1) Null Hypothesis and Alternative Hypothesis

$\mathrm{H}_{0}$ : Identified factors affect the use of digital wallets in Sri Lankan students who study in western province universities 
$\mathrm{H}_{\mathrm{a}}$ : Identified factors do not affect the use of digital wallets in Sri Lankan students who study in western province universities.

\section{2) Select Population}

"The backbone of the Sri Lankan economy is formed by Small and Medium Enterprises (SMEs) which is an essential sector in a competitive and efficient market" [35]. According to statistics, Sri Lanka has nearly 230,000 business owners or entrepreneurs [34]. As per the 2017 LFS reports, there are 300,855 Formal entrepreneurs in the agricultural sector and 279,990 Formal entrepreneurs in the nonagricultural sector [33]. Sri Lankan Government is planning to launch an Innovation and Entrepreneurship Strategy to improve the existing low number of entrepreneurs and additionally, encourage the new businessmen by supporting financially and mentoring them [34]. Digital wallet usage by business founders is important to increase wallet usage since consumers cannot use a digital wallet when buying if the merchant is not using a digital wallet. Hence identifying what a merchant requires through a digital wallet and what consumers expect from a digital wallet is important. In Sri Lanka successful businesses operated mostly by individuals who are graduates or post graduates. Statistics show that $73 \%$ of the Founders of Businesses are having a bachelor's degree or above while $40 \%$ are from computer science background and 31\% are from Business Background [39].

According to the Sri Lanka startup report 2019, the Technical skills and expertise is the factor which affects enabling of successful startups with $69 \%$ of impact [39]. As per the Sri Lanka startup report 2019, 33\% of Sri Lankan Startup Founders are between 25 - 29 [39]. According to the 2018 Startup Genome Report, the trend has changed in Sri Lanka and most entrepreneurs are the ones who have formal education, experience and whose median age is 39 years [39]. Due to the above stated reasons and existing statistics, in order to conduct the research on Finding the factors which affect the use of digital wallets in Sri Lanka, students who are studying at universities of Colombo District will be considered.

Population of the study comprised of the students studying in undergraduate, postgraduate and Ph.D programs of Western Province universities. According to the Department of Census and Statistics Sri Lanka, the western province has the highest computer literacy in the country with $38.6 \%$ in 2017 [6].

3) Sample

Since the population size for the study is above 500, a sample will be selected. Individuals will be selected independently of the other members of the population which will generate a random sample.

According to UGC Statistics 2015, Universities and HEIs established under the Universities Act,

\begin{tabular}{|l|l|}
\hline University Program (2015) & $\begin{array}{l}\text { Number of } \\
\text { Students }\end{array}$ \\
\hline $\begin{array}{l}\text { Total Undergraduate } \\
\text { Admissions }\end{array}$ & 36,582 \\
\hline Total Postgraduate Admissions & 14,120 \\
\hline $\begin{array}{l}\text { Total State University Students } \\
\text { in Western Province }\end{array}$ & 50,702 \\
\hline
\end{tabular}

Table 2: Total Population

Assumptions

1. Average university admissions are approximately equal to admissions in 2015.

Exclusions

1. Private universities are excluded due to the unavailability of statistics.

To calculate the sample size, the following formula is used,

$\mathrm{n}=\mathrm{N}^{*} \mathrm{X} /(\mathrm{X}+\mathrm{N}-1)$, 
where,

$$
\mathrm{X}=\mathrm{Za} / 22-^{*} \mathrm{p}^{*}(1-\mathrm{p}) / \mathrm{MOE} 2 \text {, }
$$

and $\mathrm{Za} / 2$ is the critical value of the Normal distribution at a/2 (e.g. for a confidence level of $95 \%$, $\alpha$ is 0.05 and the critical value is 1.96), $\mathrm{MOE}$ is the margin of error, $\mathrm{p}$ is the sample proportion, and $\mathrm{N}$ is the population size. Note that a Finite Population Correction has been applied to the sample size formula.

According to the calculations, it is planned to collect 382 responses for the questionnaire to achieve a confidence level of $95 \%$ and a $5 \%$ margin of error.

Gathering of data will be done through conducting an online survey to the selected random sample. Once gathered, the data will be analyzed to create useful information and it will be a quantitative analysis.

\section{CONClusion AND Future Research Directions}

Adopting eWallet and related technologies improve the performance of SMEs. As explained in the research design, university students who have a high level of education have a higher potential for starting SMEs. Identifying the factors influencing e-wallet adoption through the responses of students studying at universities in the Western Province will undoubtedly become a major area of study in strategy and development. management of SMEs. The Western Province is a province which has many business-centric cities and has high computer literacy compared to other parts of the country. Conducting the study for the selected population using the conceptual model selected will be beneficial for e-wallet developers and proprietary companies/banks, to focus more on the factors that affect eWallet use, and to provide functionality and features in eWallet, based on these factors.

The questionnaire will consist of three sections; the first section was intended to capture the demographics of users; the second section contained items capturing UTAUT-3 statements on a seven-point likert rating scale with end points "strongly disagree" and "strongly agree" [46]. The third section was assigned to capture usage details and experience.

As a contribution to the field of study, the above-mentioned factors can be tested through a pilot test and provide insight to discover a plan to overcome information technology barriers in the implementation of the solution. eWallet in companies.

\section{REFERENCES}

[1]. "Global Online Payment Statistics 2019", Vapulus Blog, 2019. [Online]. Available: https://www.vapulus.com/en/online-payment-statistics-2019/. [Accessed: 06- Oct- 2019].

[2]. " Sri Lankan Customers' Behavioural Intention to Use Mobile Banking: A Structural Equation Modelling Approach", Seu.ac.lk, 2019. [Online]. Available: http://www.seu.ac.lk/jisit/publication/v2n2/paper1.pdf. [Accessed: 06- Oct- 2019].

[3]. B. Pachpande and A. Kamble, "Study of E-wallet Awareness and its Usage in Mumbai", Journal of Commerce and Management Thought, vol. 9, no. 1, p. 33, 2018. Available: 10.5958/0976478x.2018.00004.6.

[4]. "El modelo chino que mira Galperín para que ML valga u\$s $30.000 \mathrm{M} "$, El modelo chino que mira Galperín para que ML valga u\$s 30.000 M, 2019. [Online]. Available: https://theworldnews.net/arnews/el-modelo-chino-que-mira-galperin-para-que-ml-valga-u-s-30-000-m. [Accessed: 06- Oct- 2019].

[5]. "The rise of digital and mobile wallet: Global usage statistics from 2018", Payments Cards \& Mobile, 2019. [Online]. Available: https://www.paymentscardsandmobile.com/mobile-wallet-global-usagestatistic/. [Accessed: 06- Oct- 2019]

[6]. Statistics.gov.lk. (2019). Computer Literacy. [online] Available at: http://www.statistics.gov.lk/education/ComputerLiteracy/ComputerLiteracy-2018Q1-Q2-final.pdf [Accessed 1 Dec. 2019].

[7]. S. Singh Rana, "A STUDY OF PREFERENCE TOWARDS THE MOBILE WALLETS AMONG THE UNIVERSITY STUDENTS IN LUCKNOW CITY", vol. 04, 2017. [Accessed 1 February 2020].

[8]. L. LTD, "The Island", Island.lk, 2020. [Online]. Available: http://island.lk/index.php?page_cat=articledetails\&page $=$ article-details\&code_title=208127. [Accessed: 08- Feb- 2020]. 
[9]. "Sampath Wepay - by Sampath Bank PLC - Finance Category - AppGrooves: Get More Out of Life with iPhone \& Android Apps", Appgrooves.com, 2020. [Online]. Available: https://appgrooves.com/ios/1375437357/sampath-wepay/sampath-bank-plc. [Accessed: 08- Feb2020].

[10]. "Sampath Bank offers customers and non-customers a variety of solutions for bill payments | Daily FT", Ft.lk, 2020. [Online]. Available: http://www.ft.lk/financial-services/Sampath-Bank-offers-customersand-non-customers-a-variety-of-solutions-for-bill-payments/42-682596. [Accessed: 08- Feb- 2020].

[11]."WePay - Electronic Banking - Personal - Sampath Bank PLC", Sampath.lk, 2020. [Online]. Available: https://www.sampath.lk/en/personal/electronic-banking/wepay. [Accessed: 08- Feb- 2020].

[12].2020.[Online].Available:https://www.researchgate.net/publication/315619951_FACTORS_AFFECTIN G_CONSUMER'S_CHOICE_TO_USE_MOBILE_WALLET_TO_ACCESS_MCOMMERCE_INDUSTRY_IN_INDIA. [Accessed: 05- Mar- 2020].

[13].B. Young, "The Rise of Digital \& Mobile Wallets: 2020 Global Usage Stats", Merchant Machine, 2020. [Online]. Available: https://merchantmachine.co.uk/digital-wallet/. [Accessed: 05- Mar- 2020].

[14]. Lankaclear.com, 2020. [Online]. Available:

https://www.lankaclear.com/assets/images/downloads/annual-reports/file/2017-2018.pdf. [Accessed: 05- Mar- 2020].

[15]."LankaClear", Lankaclear.com, 2020. [Online]. Available: https://www.lankaclear.com/products-andservices/justpay/. [Accessed: 05- Mar- 2020].

[16].Play.google.com, 2020. [Online]. Available: https://play.google.com/store/apps. [Accessed: 05- Mar2020].

[17].Statistics.gov.lk, 2020. [Online]. Available: http:/ / www.statistics.gov.lk/samplesurvey/LFS_Annual\%20Report\%202018-f.pdf. [Accessed: 05- Mar2020].

[18].Ugc.ac.lk, 2020. [Online]. Available: http://www.ugc.ac.lk/downloads/statistics/stat_2015/Chapter\%203.pdf. [Accessed: 06- Mar- 2020].

[19].2020. [Online]. Available: https://www.researchgate.net/figure/UTUAT-ConceptualModel_fig1_292134289. [Accessed: 05- Mar- 2020].

[20].2020.[Online].Available:https://www.researchgate.net/publication/292134289_REVIEW_OF_STUDIES _WITH_UTAUT_AS_CONCEPTUAL_FRAMEWORK. [Accessed: 05- Mar- 2020].

[21]. "Guerrilla marketing", En.wikipedia.org, 2020. [Online]. Available: https://en.wikipedia.org/wiki/Guerrilla_marketing. [Accessed: 05- Mar- 2020].

[22]."Consumer adoption of mobile banking in Jordan: Examining the role of usefulness, ease of use, perceived risk and self-efficacy | Emerald Insight", Doi.org, 2020. [Online]. Available: https://doi.org/10.1108/JEIM-04-2015-0035. [Accessed: 05- Mar- 2020].

[23].Ugc.ac.lk, 2020. [Online]. Available: http://www.ugc.ac.lk/downloads/statistics/stat_2015/Chapter\%203.pdf. [Accessed: 06- Mar- 2020].

[24]. "Statistics - Telecommunications Regulatory Commission of Sri Lanka", Trc.gov.lk, 2020. [Online]. Available: http://www.trc.gov.lk/2014-05-13-03-56-46/statistics.html. [Accessed: 05- Mar- 2020].

[25]. A. Goswami and S. Dutta, "Gender Differences in Technology Usage-A Literature Review", Open Journal of Business and Management, vol. 04, no. 01, pp. 51-59, 2016. Available: https://www.researchgate.net/publication/290475791_Gender_Differences_in_Technology_UsageA_Literature_Review/link/5699eca508aeeea98594c622/download.

[26].K. Mutaqin and E. Sutoyo, "Analysis of Citizens Acceptance for e-Government Services in Bandung, Indonesia: The Use of the Unified Theory of Acceptance and Use of Technology (UTAUT) Model", Bulletin of Computer Science and Electrical Engineering, vol. 1, no. 1, pp. 19-25, 2020. Available: 10.25008/bcsee.v1i1.3.

[27]."Extending the unified theory of acceptance and use of technology (UTAUT) model - IEEE Conference Publication", Ieeexplore.ieee.org, 2020. [Online]. Available: https:/ / ieeexplore.ieee.org/document/6014530. [Accessed: 09- Jul- 2020].

[28].Statistics.gov.lk. 2020. Computer Literacy Of Sri Lanka. [online] Available at: <http:/ / www.statistics.gov.lk/CLS/> [Accessed 9 July 2020].

[29].Finstad, K., 2010. The Usability Metric for User Experience. Interacting with Computers, [online] 22(5), pp.323-327. Available at: <https://www.sciencedirect.com/science/article/abs/pii/S095354381000038X>.

[30].Usabilitygeek.com. 2020. [online] Available at: <https://usabilitygeek.com/usability-metrics-a-guideto-quantify-system-usability/> [Accessed 9 July 2020].

[31].sergeev, a., 2020. UI Designer - ISO-9241 Efficiency Metrics - Theory Of Usability. [online] Uidesigner.net. Available at: <http://ui-designer.net/usability/efficiency.htm> [Accessed 9 July 2020].

[32].Measuringu.com. 2020. [online] Available at: <https://measuringu.com/seq10/> [Accessed 9 July 2020]. 
[33].Statistics.gov.lk. 2020. Sri Lanka Labour Force Survey. [online] Available at: <http://www.statistics.gov.lk/samplesurvey/LFS_Annual\%20Report_2017_version2.pdf> [Accessed 9 July 2020].

[34].Ft.lk. 2020. [online] Available at: <http://www.ft.lk/mobile/front-page/Govt--tolaunch\%C2\%A0Innovation-and-Entrepreneurship-Strategy/44-651311> [Accessed 9 July 2020].

[35].Aeb.wyb.ac.lk. 2020. [online] Available at: <http://aeb.wyb.ac.lk/wp-content/uploads/2018/01/Vo11/Kuluppuarachchi.pdf $>$ [Accessed 9 July 2020].

[36]. “Sampath.lk. 2020. Sampath Saviya - Entrepreneur Development - Personal - Sampath Bank PLC." [online] Available at: <https://www.sampath.lk/en/personal/entrepreneur-development/sampathsaviya> [Accessed 9 July 2020].

[37].Frimi.lk. 2020. Frimi. [online] Available at: <https://www.frimi.lk/frimi-for-business> [Accessed 9 July 2020]

[38].Sdb.lk. 2020. [online] Available at: <https://www.sdb.lk/en/sme/sme-plus> [Accessed 9 July 2020].

[39]."Sri Lanka Startup Report 2019 - Slasscom", Slasscom.lk, 2020. [Online]. Available: https://slasscom.lk/sri-lanka-startup-report-2019/. [Accessed: 09- Jul- 2020].

[40]."S. Subramanian, "Consumer Acuity On Select Digital Wallets", researchgate.net, 2020. [Online]. Available:

https://www.researchgate.net/publication/338357685_Consumer_Acuity_On_Select_Digital_Wallets. [Accessed: 09- Jul- 2020].

[41].Surveymonkey.com. 2020. A Study On Degree Of Awareness About Mobile Wallet, Its Potential Market In India, Barriers And Drivers To Its Success. Survey. [online] Available at: <https://www.surveymonkey.com/r/mobile_wallet_symbiosis> [Accessed 9 July 2020].

[42].V. Patel, "Young Consumers' Intention to Use Mobile Wallet Services: An Empirical Investigation Using UTAUT Model", researchgate, 2020. [Online]. Available:

https://www.researchgate.net/publication/303685121_Young_Consumers\%27_Intention_to_Use_Mob ile_Wallet_Services_An_Empirical_Investigation_Using_UTAUT_Model. [Accessed: 09-Jul- 2020].

[43].Pande, J., 2019. Cashless Transaction - Mobile Transaction. SSRN Electronic Journal, [online] Available at: <https://www.researchgate.net/publication/339253038_Impact_of_mobile_wallets_o

[44].Subaramaniam, K., 2020. The Impact of E-Wallets for Current Generation. Journal of Advanced Research in Dynamical and Control Systems, [online] 12(01-Special Issue), pp.751-759. Available at: <https://www.researchgate.net/publication/339236716_The_Impact_of_EWallets_for_Current_Generation/link/5e583914299bf1bdb840a5a9/download>

[45].A. Goswami and S. Dutta, "Gender Differences in Technology Usage-A Literature Review", Open Journal of Business and Management, vol. 04, no. 01, pp. 51-59, 2016. Available: https://www.researchgate.net/publication/290475791_Gender_Differences_in_Technology_UsageA_Literature_Review/link/5699eca508aeeea98594c622/download.

[46].A. Gurusinghe, "The adequacy of UTAUT-3 in interpreting academician's adoption to e-Learning in higher education environments | Emerald Insight", Emerald.com, 2020. [Online]. Available: https://www.emerald.com/insight/content/doi/10.1108/ITSE-05-20190020/full/html?skipTracking=true. [Accessed: 11- Aug- 2020].

[47]."An empirical study on the adoption of consumer-to-consumer e-commerce: Integrating the UTAUT model and the Initial Trust model", Research Gate, 2020. [Online]. Available: https://www.researchgate.net/publication/324676519_An_empirical_study_on_the_adoption_of_cons umer-to-consumer_e-commerce_Integrating_the_UTAUT_model_and_the_Initial_Trust_model. [Accessed: 23- Aug- 2020].

[48]."Malhotra, Nunan \& Birks, Marketing Research: An applied approach, 5th Edition | Pearson", Pearson.com, 2020. [Online]. Available: https://www.pearson.com/uk/educators/higher-educationeducators/program/Malhotra-Marketing-Research-An-applied-approach-5th-

Edition/PGM1638972.html. [Accessed: 17- Oct- 2020].

[49]."Payments Bulletin", Cbsl.gov.lk, 2020. [Online]. Available: https://www.cbsl.gov.lk/sites/default/files/Payments\%20Bulletin\%202019\%20Q1\%20Final.pdf. [Accessed: 21- Oct- 2020].

[50]. “Factors Affecting Consumer's Choice to Use Mobile Wallet to Access m-Commerce Industry in India. India: Abhilasha Seam*, Raja Sekhar Reddy*, Snehil Agrawal*, Behara Krishna Chaitanya*, Himanshu Bist*, Suleman Safdar*, Pranav Ranjan Patil*, Purba Halady Rao**, 2020.

[51].[51] "A Model of Factors Influencing Consumer's Intention To Use E-payment System in Indonesia", ResearchGate, 2020. [Online]. Available:

https://www.researchgate.net/publication/283162078_A_Model_of_Factors_Influencing_Consumer's_ Intention_To_Use_E-payment_System_in_Indonesia. [Accessed: 30-Oct- 2020].

[52].[52] “D. Lam, "The Demography Of Youth In Developing Countries And Its Economic Implications", Openknowledge.worldbank.org, 2020. 
[Online].Available:https://openknowledge.worldbank.org/handle/10986/9215. [Accessed: 30- Oct2020].

[53].[53] "The World Bank In Sri Lanka", World Bank, 2020. [Online]. Available: https://www.worldbank.org/en/country/srilanka/overview. [Accessed: 30- Oct- 2020]. 